\title{
A Study on Art Design using Vague Set Theory
}

\author{
Fang Lu \\ Academy of Fine Arts, Dalian University, Dalian, China, 116622 \\ E-mail:shining_112@live.cn
}

Keywords: Vague set; Art design; Evaluation method; Vague value.

\begin{abstract}
Art design is an innovation action in modern society; so many people pay more attention on this action. While, with the rapid growth in the number of art works, how to assess the quality of work is an important issue to decision makers. Meanwhile, lots of the theory of vague set can be used in this case of art design by analyzing the features of art design. Using statistic method, the vague value of works of art design is constructed. So the appraise of art work was transferred to the calculation of different vague value. And with the characteristics which vague value is an interval value, eigenvector is introduced to rank vague value. So, the evaluation and assessing are realized in line with the result of ranking. This method not only provides a scientific method to policy makers, but also help artist find a new way for evaluation of works of art design.
\end{abstract}

\section{Introduction}

Art design is an important component of human civilization [1].Based on the differences of the North-South customs and habits, the performance style is also very different. As a result, the content of the art is rich in diverse forms. With a large number of research analysis, the following characteristics can be summarized in the aspect of the form of art: $\mathrm{CD}$ rich details; obvious characteristics; extensive use of the plane constitute elements, such as symmetry and arrays; decorative design elements.

While with the development of art design, more and more works of art design are designed. So, how to evaluate the work of art design is an issue to decision maker. There are many method used in the evaluation of art design, such as expert review method[2], Delphi method, fuzzy evaluation method and so on. Every method has their own advantages, but also has their own drawbacks. For example, the expert review has strong subjective, uncontrollable human factors, human vulnerability, the interests of some non-scientific factors such as the interference of the evaluation results of the scientific and rationality; the Delphi method only focused on the evaluation of the signal factor, and therefore the overall effect is difficult to project a comprehensive analysis and comprehensive evaluation. Fuzzy evaluation method using fuzzy mathematics theory, a rough qualitative indicator divided into several different levels, then level with a quantitative method of evaluation. As a result, this method only can evaluate the merits of art design, but find the difference between works. On the other hand, Evaluation of works of art design is inseparable from the aesthetic of personal, so expert review is inevitably in the field. If we can get a consistency conclusion, the evaluation of works of art is science and fair. The emergence of vague set provided a new opportunity for realize this idea. 


\section{Basic Notions of Vague Set}

The theory of sets introduced by Cantor based on the notion of element membership to sets has proved itself to be one of the most powerful tools of what is known as Modern Mathematics and it has allowed us to study modeling and development of other science. However, the notion of element membership to a set is a bivalent concept, governed by the values 0 (there is no membership) and 1 (there is membership) and it does not allow other set possibilities which, nevertheless, have been studied in the fields of Logic models. Zadeh [3] suggests the creation of what are called fuzzy sets which base their development on the idea that the membership of an element to a set is indicated by a number between 0 and 1 , having for 0 non-memberships, for 1 membership and for the numbers between 0 and 1 different degrees of membership. Such sets have proved very useful in the description of phenomenon governed by imprecise parameters as well as for the development of non-bivalent Logic models [4].

Vague sets [5] proposed by Gau and Buehrer which same with intuitionistic fuzzy sets [6] introduced by Atanassov K. It is a promotion of fuzzy sets introduced by Zadeh [7]. Vague sets is characterized by taking into account the information of support, opposition and abstention, which makes Vague sets have more capacity of express than traditional fuzzy sets in dealing with uncertain information [8]. At present, vague sets have been used successfully indecision analysis, expert systems [9], fuzzy control and fault diagnosis and so on, which have achieved better results than traditional fuzzy set theory [10].

Table.1Illustration of vague sets

\begin{tabular}{|c|c|c|}
\hline category & Interactive element & Appreciation element \\
\hline Videointeractive artwork & Spactator's image,Moving, touch etc. & Result Video \\
\hline Gameinteractiveart & Spactator's control. & Match playing. \\
\hline SoundInteractiveart & Spactator's sound & Result Video \\
\hline SensorInteractiveart & Spactator's action insensor & Getting someResult \\
\hline
\end{tabular}

\section{Ranking of Works Based on Eigenvector}

Vague value is an interval value. So the comparison of vague value reflects the merits of works of art.In this kind of art, spectators don't have to control any kinds of tools. Most real-time image process installation interactive art work is very immediate. We can apply insight learning in these kinds of art work. Usually, process of interactive art work appreciation is as follows. First, spectators encounter interactive art work. And consider a way how to operate the interactive art work. Next, operate the work. So, spectators can get artistic result or feedback. In this process, game and art work is little different. There is definite answer or goal in game process, but in art it is little difficult to define the answer or goal. Artists just explain and pursue their philosophy through the art work. But interactive art, there have to be definite process of interacting like game playing process.

Let $U$ is a domain, with a generic element of $U$ denotedby $x$. A real value vague sets in $U$ is characterized by atruth-membership function $t_{A}$ and a false-membershipfunctionf ${ }_{A}$.

$$
\mathrm{t}_{\mathrm{A}}: \mathrm{U} \rightarrow[0,1], \mathrm{f}_{\mathrm{A}}: \mathrm{U} \rightarrow[0,1]
$$

$\mathrm{x} \in \mathrm{U}, \mathrm{t}_{\mathrm{A}}(\mathrm{x})$ is a lower bound of certain degree of membership of $\mathrm{x} \in \mathrm{A}$ derived from the evidence for $x \in A$, and $f_{A}$ is a lower bound of negative membership of $x \in A$ derived from the evidence against $\mathrm{x} \in \mathrm{A}$. Moreover,

$$
\mathrm{t}_{\mathrm{A}}(\mathrm{x})+\mathrm{f}_{\mathrm{A}}(\mathrm{x}) \leq 1(2)
$$

Themembership of $x$ on $A$ is donated by the sub-interval $\left[t_{A}(x), 1-f_{A}(x)\right]$ of $[0,1]$, either, $\left[t_{A}(x)\right.$, $\left.1-f_{A}(x)\right]$ is the vague value of $x$ in Vague sets $A$. 
$\Omega_{\mathrm{A}}(\mathrm{x})$ is said to be the uncertaindegree(hesitation degree) of $\mathrm{x}$ relative to $\mathrm{A}$, and also isknown as hesitation or vacillation degree. $\Omega_{\mathrm{A}}(\mathrm{x})$ is the uncertain information measurement of $\mathrm{x}$ relative to $\mathrm{A}$, the larger $\Omega_{A}(x)$ value is, the more uncertain degree of $x$ relative to $A$ is. Whent $t_{A}=1-1-f_{A} \Omega_{A}(x)=0$, that is whent $t_{A}(x)+f_{A}(x)=1$, Vague value $x$ is degradation for general fuzzy value.

\section{Analysis Vague Game Art}

When spectators appreciate interactive art work they areconfronted by how control method or how appreciateinteractive work. So, interactive artists have to choice the easyand also artistic way of interacting. When artists plan theinteractive art work, it will be very systematic if they applylearning systems. In addition, many kinds of gamecontrollers are very popular interactiveart instrument. Many digital artists like to use game controllers. This kinds of controllers are very easy to control when makedigital art. Definitely, boundary between game and art isgetting vanish.
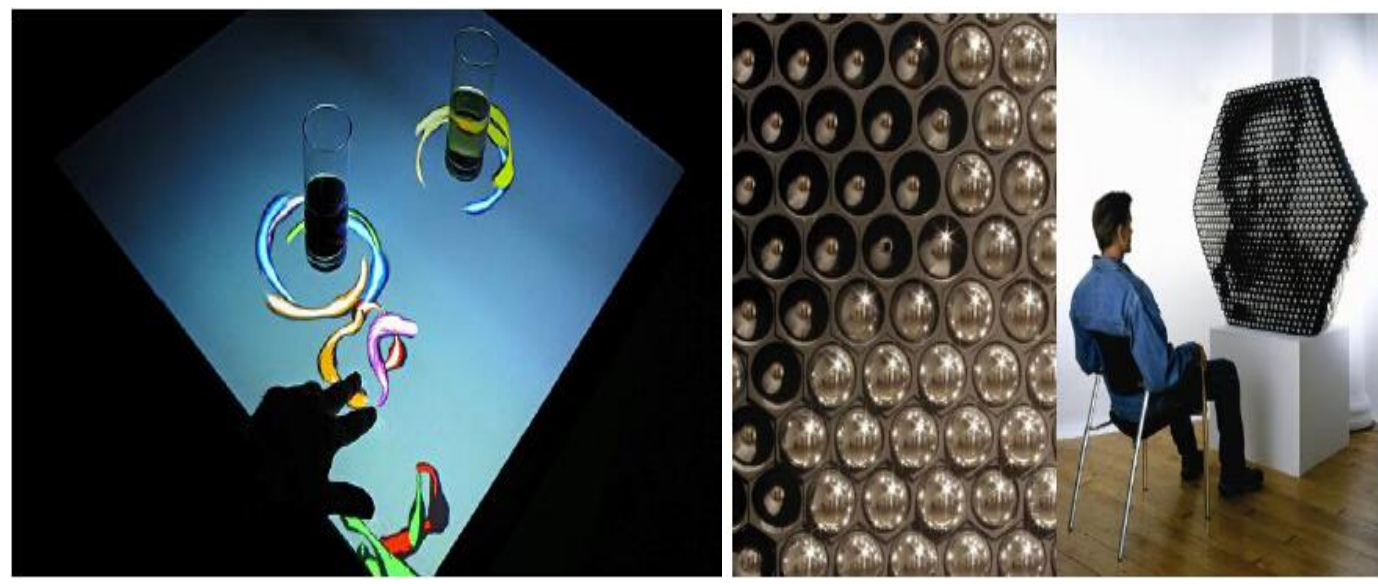

Figure1.Shiny Balls Mirror

\section{Conclusions}

The work of art design develops rapidly these years in our country. However, there are still imperfect in the evaluation system. In this paper, the theory of vague set is used in the process of evaluation. This method can better respond the works of art design works in the characteristics in the evaluation process. Meanwhile, the method can accurately reflect the uncertainty in the evaluation process and the different understanding of experts' to same works. With the Vague set theory, the work of art design can be expressed by vague value. Then, the vague value of work can reflect the popularity of the work one hand; on the other hand, it is a foundation to calculate the similarity between works. Meanwhile, the method provides a scientific method to policy makers, also help artist find a new way for evaluation of works of art design.

\section{Acknowledgement}

This work was supported by the Liaoning Provincial Education Department (W2013280); Scientific Research Foundation for the Returned Overseas Chinese Scholars, State Education Ministry; Research Fund for the Doctoral Program of Dalian University. 


\section{References}

[1] Y. Qi, X. Zhou, "Enlightenment of artistic features of soul vase in Wei and Jin Dynasties on modern art design of ceramics," Computer-Aided Industrial Design \& Conceptual Design (CAID/CD2009), 2009: pp.1712-1714

[2] L. Gao, D. Peng, X. Liu, S Yu, "Digital aided technology research on Chinese traditional art design - case for paper-cut," Computer-Aided Industrial Design and Conceptual Design (CAID/CD2008), 2008: pp.1349-1354

[3] W. L. Gau, D. J. Buehrer, "Vague sets," IEEE Trans Syst. Man Cybern., 1993, 23 (2): pp.610-614.

[4] W. Wang, Q. Wu, X. Hu, "Basic Rules and General Method on Similarity Measures between Vague Sets," Proceedings of 2007 International conference on wavelet Analysis and Pattern Recognition, ICWPR, Beijing, China, 2007: pp.1294-1299, 2007.

[5] C. Cui, Q. Wu, X. Zhai, "Similarity Measure of Vague Value Based on Dependent Function," Xuzhou: 2010 Chinese Control and Decision Conference (2010 CCDC): pp. 632 - 635

[6] C. Cui, Q. Wu, "Research on Electric Commerce Recommender Systems Based on Vague Set,"

Nanjing: First IEEE International Conference on Information Science and Engineering, 2009 pp.5382-5385.

[7] F. Hou, Q. Wu, "Eigenvector Method for Ranking Alternatives with Vague Value Measurements," Journal of Beijing Institute of Technology, 2009, 18(2): pp. 247-252

[8] M. Radu, C. Cole, M. Dabacan, J. Harris, S. Exton, “Improving students' hardware and software skills by providing unrestricted access to state of the art design tools and hardware systems," Microelectronic Systems Education(MSE), 2009: pp. 65-68

[9] J. Liu; Q. Zhang; Q. Cheng, "Study on the application of team communication patterns in art design teaching," Environmental Science and Information Application Technology (ESIAT), 2010(3): pp.569-572

[10] C. Cui, Q. Wu. "Research on Content-based Recommendation based on Vague Sets," Application Research of Computers, 2010, 27(6): 2109-2111 